\title{
Portal hypertension in a patient with chronic myeloid leukaemia
}

\author{
MINOU D. FOADI \\ M.D. \\ S. SHAW \\ M.D., F.R.C.Path. \\ F. J. PARADINAS \\ M.R.C.Path.

\begin{abstract}
Departments of Haematology and Histopathology, Charing Cross Hospital Medical School, London, W.6
\end{abstract}

\begin{abstract}
Summary
A patient with chronic myeloid leukaemia treated with busulphan for 4.5 years, developed signs of busulphan toxicity and portal hypertension with ascites, cesophageal varices and jaundice. At post-mortem there was minimal leukaemic infiltration but there were alterations in the liver architecture sufficient to explain the portal hypertension. The pathogenesis of the liver changes and their possible relationship to splenomegaly and busulphan toxicity are considered.
\end{abstract}

\section{Introduction}

Portal hypertension in myeloproliferative disorders has been reported in the past (Shaldon and Sherlock, 1962; Blendis et al., 1970b) but only very rarely has this given rise to symptoms, and the pathogenesis is obscure. Sub-clinical portal hypertension has been recorded in seven patients with chronic myeloid leukaemia (Datta et al., 1975) who had no jaundice or ascites. The present patient with chronic myeloid leukaemia developed clinical features of portal hypertension.

\section{Case report}

A 58-year-old white man was found to have chronic myeloid leukaemia during a hospital admission for minor surgery. After 18 months, the spleen was just palpable and there was a marked rise in white blood cells $\left(89 \times 10^{\circ} / 1\right)$ and platelets $\left(1000 \times 10^{\%} / 1\right)$. The leucocyte alkaline phosphatase score was reduced to 1 and the Philadelphia chromosome was demonstrated.

Busulphan $4 \mathrm{mg} /$ day was given for 6 weeks. The patient was then maintained with $2 \mathrm{mg}$ of busulphan/ day or alternate days for 54 months. The spleen was not palpable during most of this time and the patient was well except for a temporary mild diabetes during 1973 which was controlled with chlorpropamide $(100 \mathrm{mg}$ daily initially, reducing to $100 \mathrm{mg}$ on alternate days for 4 months only).

Six years after diagnosis, he was admitted with a month's history of being unwell, with loss of energy and weight. On physical examination, there was marked wasting of the muscles-particularly around the shoulders, hyper-pigmentation of the skin over the axillae and pubic regions, and evidence of heart failure. The spleen was palpable $4 \mathrm{~cm}$ below the costal margin and there was moderate hepatomegaly. The haemoglobin was 7.1 g/dl; WBC $37.8 \times 10^{\circ} / 1$; the platelet count $170 \times 10^{\circ} / 1$. A diagnosis of busulphan toxicity was made and the drug was discontinued. The patient's condition improved with blood transfusions and diuretics. Two weeks later he was readmitted with haematemesis, and oesophageal varices were demonstrated radiologically. He then became jaundiced and developed ascites and haemorrhoids. The serum bilirubin was $85 \mu \mathrm{mol} / 1$ of which two-thirds was direct. The alkaline phosphatase was $36 \mathrm{KAu}$. and the amino-transferases were normal. The total serum protein was $59 \mathrm{~g} / \mathrm{l}$; serum albumin $35 \mathrm{~g} / 1$; IgG was $6, \operatorname{IgA} 1 \cdot 1$ and $\operatorname{IgM} 0.2 \mathrm{~g} / \mathrm{l}$; the blood urea had risen to $21 \mathrm{mmol} / \mathrm{l}$. Because of the marked ascites spironolactone was given, with partial improvement. Two liver biopsies failed to show cirrhosis and only occasional leukaemic cells in sinusoids were seen.

The patient's condition deteriorated and there was repeated severe blood loss from the gastrointestinal tract necessitating blood transfusions and he developed mild thrombocytopenia. The alkaline phosphatase had risen to about $90 \mathrm{KAu}$. and there was a rise in blood urea to $24 \mathrm{mmol} / \mathrm{l}$. Except for a rise in the alanine aminotransferase to 42 i.u./1 on one occasion, liver transaminases remained normal, but serum alkaline phosphatase showed a marked variation. The patient died from a bilateral bronchopneumonia.

At post-mortem there was no evidence of portal or hepatic vein obstruction. The bile ducts were patent, although a few pigment stones were found in the gall-bladder. The lungs showed bronchopneumonia and anisocytosis of bronchial and alveolar epithelium consistent with 'busulphan lung'. The bone marrow and spleen showed evidence of chronic myeloid leukaemia. In the liver the changes were: (a) rearrangement of some liver cell cords with 


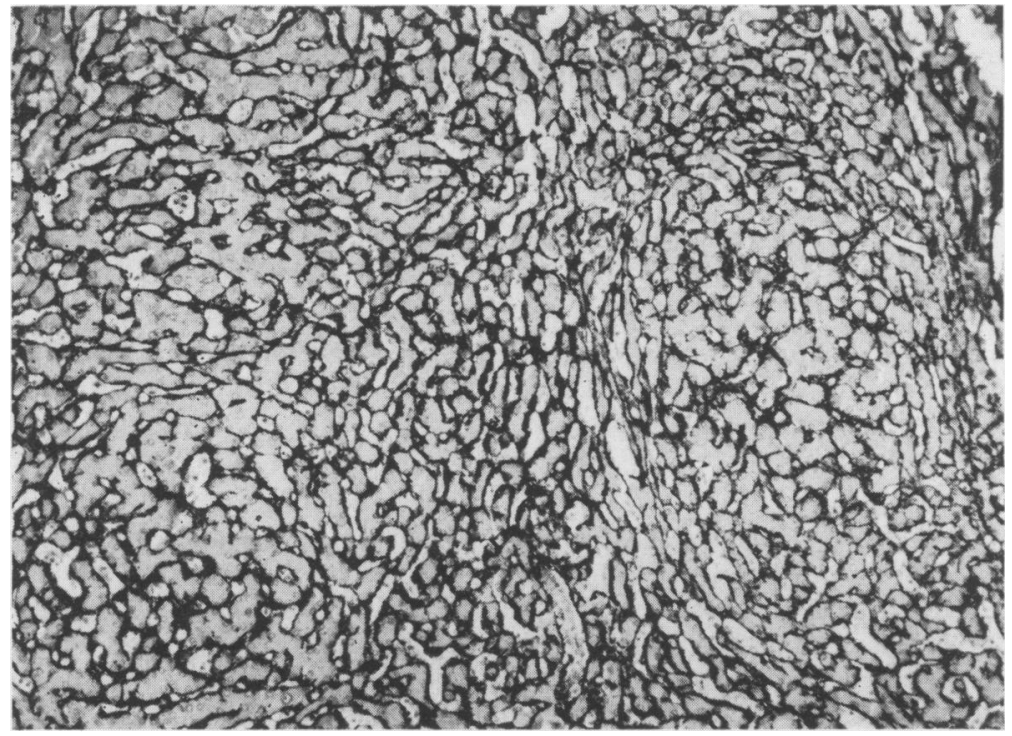

FIG. 1. Nodular formation without fibrosis in the liver. This appears to be due to rearrangement of sinusoids and nodular hyperplasia (Gordon and Sweet's silver impregnation for reticulin, $\times 100$ ).

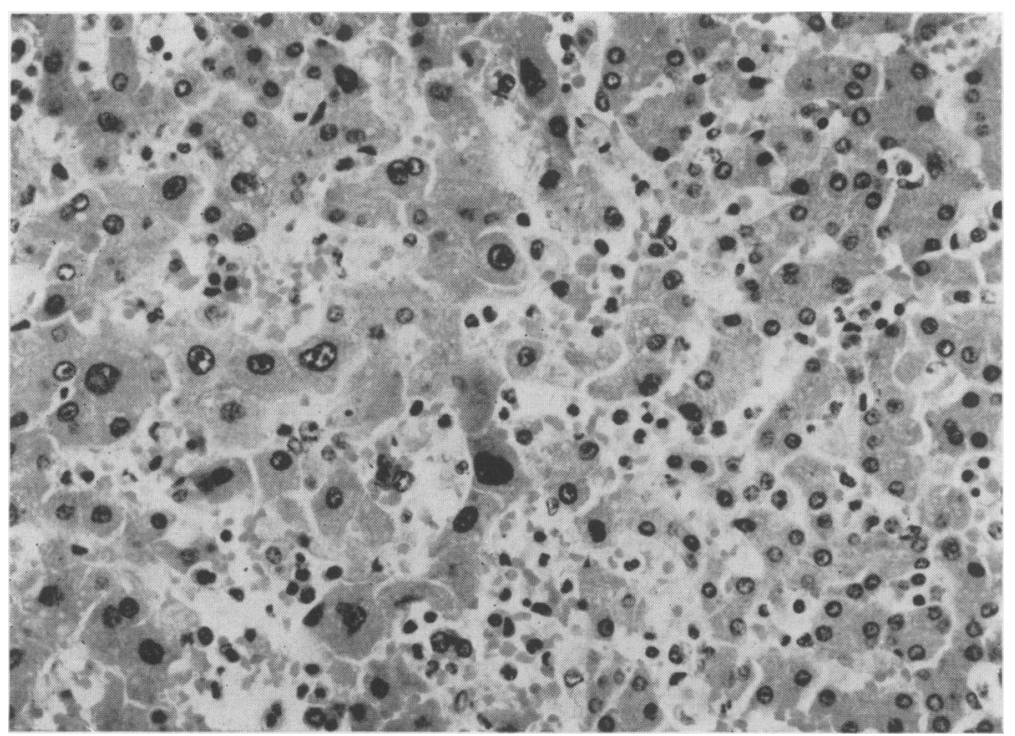

FIG. 2. Marked anisocytosis and bizarre nuclei in the liver parenchyma. The dilated sinusoids contain a few granulopoietic cells $(\mathrm{HE} \times 250)$.

formation of nodular areas, usually smaller than a lobe (Fig. 1); (b) there was fibrosis in the subcapsular area, with thin septa extending between portal tracts along the rearranged cords: this fibrosis was incomplete (no true nodules were formed) and was not present in sections from liver parenchyma deep within the organ; (c) anisocytosis, with large hepatocytes (Fig. 2); (d) very focal and inconspicuous sinusoidal infiltrations with leukaemic cells (Fig. 2); (e) cholestasis, with bile 'lakes' and dilated canaliculi within lobules and occasionally in bile ducts.

\section{Discussion}

Haemodynamic studies in patients with chronic myeloid leukaemia have been carried out in the past (Shaldon and Sherlock, 1962; Blendis et al., 1970b) 
and increased portal pressure has been found, even in the absence of portal vein thrombosis. Datta et al. (1975) compared their results from patients with chronic myeloid leukaemia with those from patients with tropical splenomegaly and concluded that splenomegaly and increased portal flow were by themselves insufficient to explain the hypertension. They postulated that sinusoidal infiltrations by leukaemic cells-which they found in liver biopsies from all their cases-were a major contributory factor by increasing resistance to the flow. The findings in the present patient appeared to be unique, differing from those previously reported in that the portal hypertension was clinically overt and postmortem examination revealed disturbances in hepatic architecture, other than infiltrations, sufficient to explain the clinical picture. Two needle biopsies during life failed to demonstrate these changes. This suggests that the cause of portal hypertension in myeloid leukaemia may not be as simple as previously thought and the full picture may only become complete when sufficient post-mortem studies are carried out.

The nature of the changes is complex and their pathogenesis obscure. The presence of anisocytosis in the liver and lung raises the possibility of busulphan toxicity as a contributory factor. The nodu- larity without diffuse fibrosis vaguely resembled that seen in Felty's syndrome (Blendis et al., 1970a). The cholestasis appeared to be related to disturbances in hepatic architecture and there was no evidence of extrahepatic obstruction nor relationship between the development of jaundice and the low-dosage short-term administration of chlorpropamide, a drug known to cause sensitivity cholestasis.

\section{Acknowledgments}

We thank Dr I. M. Murray Lyon and his staff who helped with the management of the hepatic complication in this patient and Dr G. D. Pegrum who helped with the general management.

\section{References}

Blendis, L.M., Ansell, I.D., Lloyd Jones, K., Hamilton, E. \& Williams, R. (1970a) Liver in Felty's syndrome. British Medical Journal, 1, 131.

Blendis, L.M., Banks, D.C., Ramboer, C. \& Williams, R. (1970b) Spleen blood flow and splanchnic haemodynamics in blood dyscrasia and other splenomegalies. Clinical Science, 38, 73.

DatTa, D.V., Grover, S.L., Saini, V.K., Datta, B.N., Aikat, B.K \& Chhuttani, P.N. (1975) Portal hypertension in chronic leukaemia British Journal of Haematology, 31, 279.

Shaldon, S. \& Sherlock, S. (1962) Portal hypertension in the myeloproliferative syndrome and the reticuloses. American Journal of Medicine, 32, 759.

\section{Gynaecomastia associated with gonadotrophin-secreting carcinoma of the lung}

\author{
D. FAIRLAMB \\ M.B., B.S.
}

\author{
EVELYN BOESEN \\ M.D. (London)
}

The Royal Free Hospital, Pond Street, Hampstead, London, NW3

\begin{abstract}
Summary
A 67-year-old man developed dermatomyositis. Investigation revealed an oat cell carcinoma of the lung. When he developed unilateral gynaecomastia this tumour was found to secrete gonadotrophins. The gynaecomastia disappeared after treatment with an anti-oestrogen-tamoxifen. This use of tamoxifen has not previously been described. Partial tumour regression was obtained with several cytotoxic drug regimes. His dermatomyositis responded to this treatment and remains in remission.
\end{abstract}

\section{Case report}

A 67-year-old Caucasian male was admitted in March 1975 for investigation of a rash which had been present for 3 months. He was a semi-retired pastry cook who had smoked ten cigarettes daily all his life. The pruritic rash had started on his hands and spread centrally. There was no previous history of skin disease or other significant illness. He also had generalized weakness, particularly affecting his grip. He had been extensively investigated at another hospital 1 year previously for anorexia and weight- 